\title{
Supraglottic Airway Devices Versus the Endotracheal Tube in Trendelenburg position during Gynecological Laparoscopy
}

\author{
Babayants A.V., Tikhonova I.J., Protsenko D.N. \\ Pirogov Russian National Research Medical University (RNRMU), Dept of \\ Anaesthesiology \& Intensive Care, Moscow Teaching Municipal Hospital \#52 Moscow, \\ Russian Federation
}

Background and Goal of Study: The supraglottic airway devices (SADs) (such as LMA, i-gel) have become widely popular in different types of surgical procedures. They provide a less invasive airway as compared to the endotracheal tube. The use of SADs during elective gynecological laparoscopy is still not widely accepted due to the controversies about possibility of complications of regurgitation.

Materials and methods: We conducted a prospective study of 125 patients of ASA grade I-II. All operations were performed under general anesthesia (propofol + fentanyl + rocuronium). Patients were randomly assigned to the 3 groups, I group ( $n=47$ ) having endotracheal intubation with cuffed Endotracheal Tube (ETT), in the II group (LMA) (n=40), LMA-supreme was inserted and in the III group $(n=38)$ (IGEL) i-gel was inserted. All patients underwent elective gynecological laparoscopic procedures. The average duration of surgery was $82 \pm 32,4$ minutes in all the groups. The head down tilt was between $20^{\circ}-25^{\circ}$. We observed the hemodynamic changes, peak pulmonary pressure, airway resistance at the time of induction and at 5, 15, 30 and 60 minutes after gas insufflation and at the time of extubation. We compared the total amount of opioid, anesthetic and muscle relaxant between the groups. The anesthesia depth control of was performed via BIS-monitor, depth of neuromuscular blockade was determined using TOF-monitor. We examined $\mathrm{pH}$ of oropharyngeal cavity by inserting a $\mathrm{pH}$ test strips before insertion and after removal of the SADs and ETT. In the early postoperative period a comparative evaluation between the groups in the frequency of PONV and sore throat was performed

Results and discussion: Between the two groups there were no significant differences in the consumption of anesthetic, an opioid and a muscle relaxant. The $\mathrm{pH}$ read between 6,5-7,5 in all three groups at both stages, which indirectly indicated the absence of regurgitation of acid stomach content into the oral cavity. PONV was not observed in either group. The frequency of sore throat was $52 \pm 12.7 \%$ in the ETT and Group LMA and Igel 10.5 \pm 4.3 and $11.4 \pm 4.7 \%$ respectively.

Conclusion(s): We have concluded that the using supraglottic oropharyngeal airway devices provide a sufficient level of safety during gynecological laparoscopic operations in the Trendelenburg position and improve the comfort of the patient in the postoperative period.

Sources:

1. Viira D, Myles PS. The use of the laryngeal mask in gynaecological laparoscopy. Anaesth Intensive Care. 2004;32:560-3.

2. Keijzer C, Buitelaar DR, Efthymiou KM, et al. A comparison of postoperative throat and neck complaints after the use of the i-gel and the La Premiere disposable laryngeal mask: a double-blinded, randomized, controlled trial. Anesthesia and Analgesia 2009; 109: 1092-5

3. Yu SH, Beirne OR. Laryngeal mask airways have a lower risk of airway complications compared with endotracheal intubation: a systematic review. J Oral Maxillofac Surg 2010; 68:2359-2376.

4. Mukadder S, Zekine B, Erdogan KG, et al. Comparison of the proseal, supreme, and i-gel SAD in gynecological laparoscopic surgeries. Scientific World J 2015; 2015:634320.
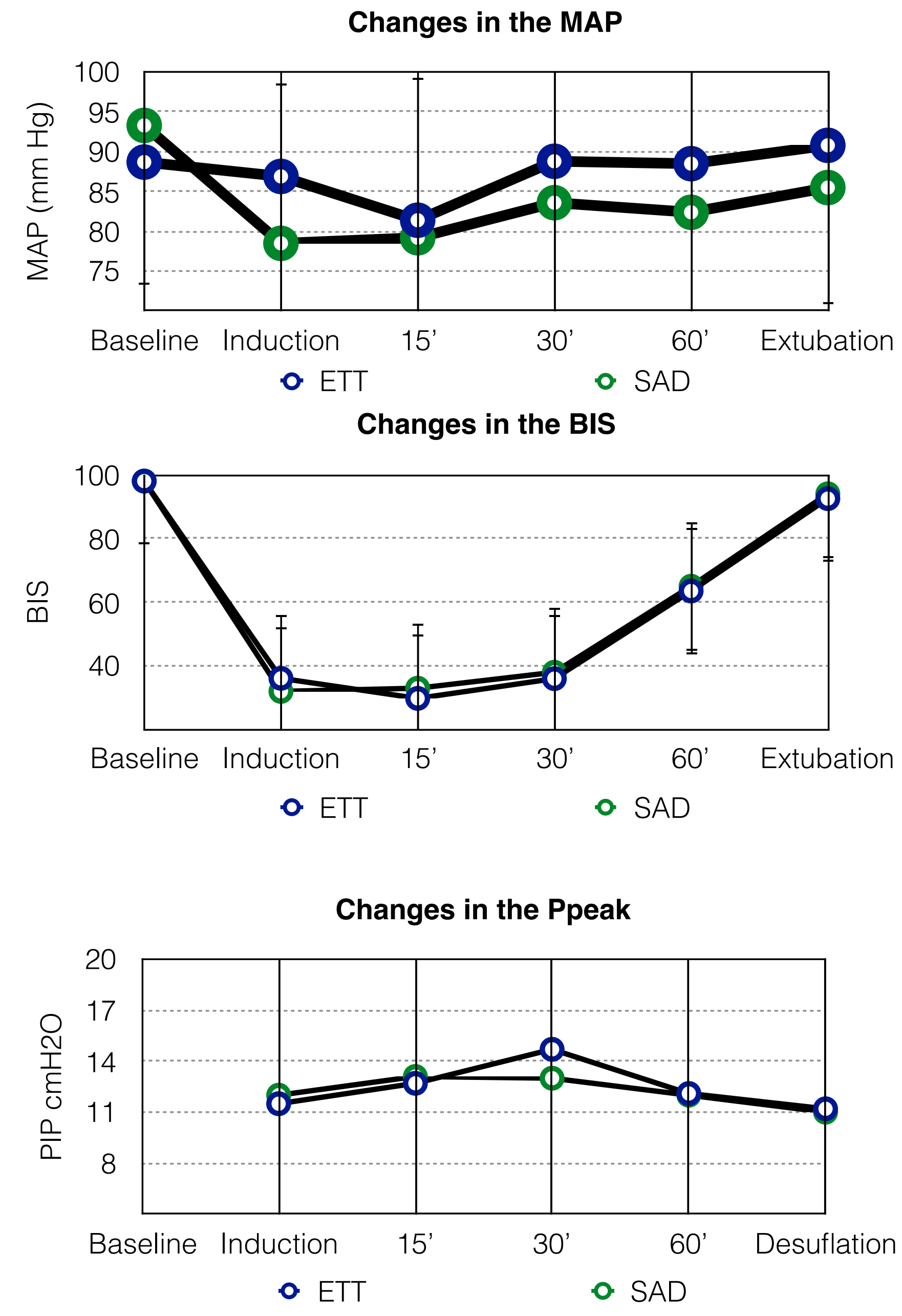

Adverse events

\begin{tabular}{|ccc|}
\hline & $\begin{array}{c}\text { ETT } \\
(\mathrm{n}=47)\end{array}$ & $\begin{array}{c}\text { SAD } \\
(\text { LMA,IGel) } \\
(\mathrm{n}=78)\end{array}$ \\
$\begin{array}{c}\text { Sore throat } \\
\text { (mild/moderate) \% }\end{array}$ & $27,7 / 8,5$ & $9 / 2,6$ \\
$\begin{array}{c}\text { Hoarseness of voice } \\
\text { (mild/moderate) \% }\end{array}$ & $4,3 / 2,1$ & $0 / 1,3$ \\
Nausea \% & 2,1 & 1,3 \\
\hline
\end{tabular}
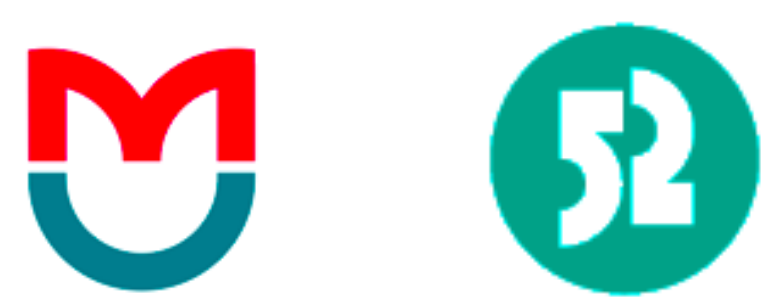

ГОРОДСКАЯ

КЛИНИЧЕСКАЯ

БОЛЬНИЦА №52

Pirogov Russian National

Research Medical University

(RNRMU) 